\title{
Utilizing Intrabolus Pressure and Esophagogastric Junction Pressure to Predict Transit in Patients With Dysphagia
}

\author{
Su Hyeon Jeong, Moo In Park, ${ }^{*}$ Hyung Hun Kim, Seun Ja Park and Won Moon \\ Department of Internal Medicine, Kosin University College of Medicine, Busan, Korea
}

\begin{abstract}
Background/Aims
High-resolution manometry (HRM), with a greatly increased number of recording sites and decreased spacing between sites, allows evaluation of the dynamic simultaneous relationship between intrabolus pressure (IBP) and esophagogastric junction (EGJ) relaxation pressure. We hypothesized that bolus transit may occur when IBP overcomes integrated relaxation pressure (IRP) and analyzed the relationships between peristalsis pattern and the discrepancy between IBP and IRP in patients with dysphagia.
\end{abstract}

\section{Methods}

Twenty-two dysphagia patients with normal EGJ relaxation were examined with a 36-channel HRM assembly. Each of the 10 examinations was performed with 20 and $30 \mathrm{mmHg}$ pressure topography isobaric contours, and findings were categorized based on the Chicago classification. We analyzed the relationships between peristalsis pattern and the discrepancy between IBP and IRP.

\section{Results}

Twenty-two patients were classified by the Chicago classification: 1 patient with normal EGJ relaxation and normal peristalsis, 8 patients with intermittent hypotensive peristalsis and 13 patients with frequent hypotensive peristalsis. A total of 220 individual swallows were analyzed. There were no statistically significant relationships between peristalsis pattern and the discrepancy between IBP and IRP on the 20 or $30 \mathrm{mmHg}$ isobaric contours.

\section{Conclusions}

Peristalsis pattern was not associated with bolus transit in patients with dysphagia. However, further controlled studies are needed to evaluate the relationship between bolus transit and peristalsis pattern using HRM with impedance.

\section{(J Neurogastroenterol Motil 2014;20:74-78)}

\section{Key Words}

Esophageal motility disorder; Manometry; Peristalsis

Received: March 6, 2013 Revised: October 10, 2013 Accepted: October 11, 2013

(c) This is an Open Access article distributed under the terms of the Creative Commons Attribution Non-Commercial License (http://creativecommons. org/licenses/by-nc/3.0) which permits unrestricted non-commercial use, distribution, and reproduction in any medium, provided the original work is properly cited.

*Correspondence: Moo In Park, MD

Department of Internal Medicine, Kosin University College of Medicine, 262, Gamcheon-ro, Seo-gu, Busan 602-702, Korea Tel: +82-51-990-6719, Fax: +82-51-990-3005, E-mail: mipark@ns.kosinmed.or.kr

Financial support: None.

Conflicts of interest: None.

Author contributions: SH Jeong performed performed statistical analysis and wrote this paper as the first author; MI Park designed this study and reviewed this paper as a corresponding author; HH Kim, SJ Park and W Moon supported the analysis of results and discussion. 


\section{Introduction}

The primary function of the esophagus is the transport of food from the mouth to the stomach. Complete bolus transit during swallowing results from a delicate balance between forces promoting esophageal clearance (peristaltic function and intrabolus pressure $[\mathrm{IBP}]$ ) and outflow obstruction at the esophagogastric junction (EGJ). ${ }^{1}$ To quantify the dynamic relationship between IBP and EGJ relaxation pressure, it is necessary to precisely measure the intraluminal pressure. ${ }^{2}$ Conventional manometry has some limitations in evaluating esophageal physiologic function. However, high-resolution manometry (HRM), with a greatly increased number of recording sites and pressure sensors, has a very rapid response time and can simultaneously monitor IBP and EGJ relaxation pressure. ${ }^{3}$

Tutuian and Castell ${ }^{4}$ suggested that abnormal bolus transit is reliant on the delicate balance between IBP and EGJ relaxation pressure. Assessing a cohort of 350 patients with dysphagia, they found that normal bolus transit can occur in a poorly relaxing EGJ if peristalsis can generate sufficient IBP to overcome EGJ relaxation pressure. Therefore, defining the balance between IBP and EGJ relaxation pressure could be helpful in predicting abnormal bolus transit. We aimed to determine relationships between each peristalsis pattern and bolus transit and assumed that bolus transit was occurring when IBP was sufficient to overcome IRP.

\section{Materials and Methods}

\section{Patients}

Patients were recruited from Kosin Gospel University, College of Medicine. HRM studies were conducted on 38 dysphagia patients. Six patients with abnormal EGJ relaxation pressure, 1 with spasm and 9 with functional obstruction were excluded. Total of 22 dysphagia patients with normal EGJ relaxation pressure and without a history of upper gastrointestinal tract surgery or any significant medical condition were recruited. Of the endoscopic findings of 22 patients, 19 atrophic gastritis, 2 erosive gastritis and 1 gastric polyp were observed. The study was a retrospective study on already acquired HRM data. This study was approved by the Kosin University Ethics Committee.

\section{High-resolution Manometry}

A solid state HRM assembly with 36 solid state sensors spaced at 1-cm intervals (Sierra Scientific Instruments, Los Angeles, CA, USA) was used. Calibration and post-study thermal correction were performed at each test. After a brief interview and examination, the HRM assembly was passed transnasally and positioned to record from the hypopharynx to the stomach. After a 5-minute rest period to assess basal sphincter pressure, 5 $\mathrm{mL}$ water swallows were performed in the supine position. HRM data were subsequently analyzed using ManoView TM analysis software (Sierra Scientific Instruments). Characterization of the pressure morphology across the esophagus and EGJ was performed with a computer program customized to display HRM data as color isocontour plots.

\section{Esophageal Pressure Topography Analysis}

Patients were characterized by EGJ pressure morphology and by the presence or absence of impaired deglutitive EGJ relaxation. For inclusion in the study, subjects were required to have normal EGJ anatomy (no hernia) and normal EGJ relaxation. Peristaltic integrity was evaluated for each swallow on isobaric contour plots of 20 and $30 \mathrm{mmHg}$. Results were categorized by the Chicago classification. Transition zone (TZ) defects greater than $2 \mathrm{~cm}$ in length were strongly associated with otherwise unexplained dysphagia and represent a distinct esophageal motility disorder that should be considered in the evaluation of dysphagia. ${ }^{5}$ When a defect was observed, it was further characterized using the standard presented from an existing dissertation: (1) normal (no break $\geq 2 \mathrm{~cm}$ ), (2) focal peristaltic hypotension (longest break $\geq 2 \mathrm{~cm}$ and $<5 \mathrm{~cm}$ ), (3) diffuse peristaltic hypotension (longest break $\geq 5 \mathrm{~cm}$ ) or (4) absent peristalsis (no pressure domain $>30 \mathrm{mmHg}$ ). ${ }^{6}$ The 2 and $5 \mathrm{~cm}$ length cutoff points were chosen based on announced dissertation asserting that breaks $<2 \mathrm{~cm}$ represent compromised bolus clearance and breaks $\geq 5 \mathrm{~cm}$ are invariably associated with incomplete clearance. Complete bolus clearance may or may not occur with intermediate size breaks from $2-5 \mathrm{~cm} .{ }^{7,8}$ Recognizing that esophageal bolus transport is affected by the balance between peristaltic function and intrabolus pressure (IBP) and integrated relaxation pressure (IRP), ${ }^{8,9}$ we analyzed relationships between each peristalsis pattern and bolus transit and assumed that bolus transit was occurring when IBP was sufficient to overcome IRP.

\section{Statistical Methods}

SPSS statistical software (version 16; SPSS, Chicago, IL, USA) was used for analyses. Data between groups were compared using the $\chi^{2}$ test for categorical data. A $P$-value $<0.05$ 
was considered significant

\section{Results}

A total of 22 dysphagia patients were studied ( 6 men; age, 39-88 years). All subjects tolerated the study well and had normal deglutitive EGJ relaxation. Twenty-two patients were classified by Chicago classification: 1 patient with normal EGJ relaxation and normal peristalsis, 8 patients with intermittent hypotensive peristalsis and 13 patients with frequent hypotensive peristalsis (Table 1). A total of 220 individual swallows were analyzed. On isobaric contour plots of $20 \mathrm{mmHg}$, 63 swallows were characterized as normal (no break $\geq 2 \mathrm{~cm}$ ), 71 swallows with focal peristaltic hypotension (longest break $\geq 2 \mathrm{~cm}$ and $<5 \mathrm{~cm}$ ), 49 swallows with diffuse peristaltic hypotension (longest break $\geq 5 \mathrm{~cm}$ ), and 37 swallows with absent peristalsis. On isobaric contour plots of $30 \mathrm{mmHg}, 35$ swallows were characterized as normal, 77 swallows with focal peristaltic hypotension, 71 swallows with diffuse peristaltic hypotension and 37 swallows with absent peristalsis (Table 2).

Between normal peristalsis swallows and absent peristalsis

Table 1. Chicago Classification

Diagnostic criteria for esophageal motility $\quad$ No. of patients (\%)

With normal EGJ relaxation (mean IRP $<15 \mathrm{mmHg}$ ) and normal IBP Normal peristalsis $1(4.5)$

Hypotensive peristalsis

$\begin{array}{lc}\text { Intermittent } & 8(36.4) \\ \text { Frequent } & 13(59.1) \\ \text { Absent peristalsis } & 0(0.0)\end{array}$

EGJ, esophagogastric junction; IRP, integrated relaxation pressure; IBP, intrabolus pressure.

Table 2. Peristaltic Pattern

\begin{tabular}{clc}
\hline Isobaric contour & \multicolumn{1}{c}{ Peristaltic pattern } & $\mathrm{n}(\%)$ \\
\hline \multirow{2}{*}{$20 \mathrm{mmHg}$} & Normal & $63(28.6)$ \\
& Focal peristaltic hypotension & $71(32.3)$ \\
& Diffuse peristaltic hypotension & $49(22.3)$ \\
& Absent peristalsis & $37(16.8)$ \\
$30 \mathrm{mmHg}$ & Total & 220 \\
& Normal & $35(15.9)$ \\
& Focal peristaltic hypotension & $77(35.0)$ \\
& Diffuse peristaltic hypotension & $71(32.3)$ \\
& Absent peristalsis & $37(16.8)$ \\
& Total & 220
\end{tabular}

swallows, there were statistically significant relationships for peristalsis pattern and bolus transit on isobaric contours of 20 and 30 $\mathrm{mmHg}$ (both $P<0.001$ ). Between normal peristalsis swallows and focal hypotensive peristalsis swallows, there were no significant relationships for peristalsis pattern and bolus transit on isobaric contours of 20 or $30 \mathrm{mmHg}(P=0.604$ and $P=0.410$, respectively). Between normal peristalsis swallows and diffuse hypotensive peristalsis swallows, there were no significant relationships for peristalsis pattern and bolus transit on isobaric contours of 20 or $30 \mathrm{mmHg}(P=0.815$ and $P=0.499)$ (Table 3 and Figure).

\section{Discussion}

In this study, hypotensive peristalsis patterns were mainly observed in patients with dysphagia. Recent HRM studies have shown that esophageal peristalsis actually comprises 2 distinct contractile waves, corresponding to distinct muscle types and neural control mechanisms of the proximal and distal esophagus. ${ }^{10-13}$ The $\mathrm{TZ}$ represents the region of spatiotemporal merger between the 2 contractile waves. ${ }^{11,14}$ Two case reports have documented instances in which $\mathrm{TZ}$ defects identified with HRM pressure topography were associated with impaired bolus transit across the $\mathrm{TZ} .{ }^{15,16} \mathrm{TZ}$ defects represent a distinct esophageal motility disorder that should be considered in the evaluation of unexplained dysphagia. ${ }^{5}$

Esophageal bolus transit is a carefully coordinated phenomenon in which the mechanical balance among peristaltic pressure,

Table 3. Concordance Between Peristaltic Pattern and Transit

\begin{tabular}{|c|c|c|c|c|}
\hline $\begin{array}{l}\text { Isobaric } \\
\text { contour }\end{array}$ & $\begin{array}{l}\text { Peristaltic } \\
\text { pattern }\end{array}$ & $\begin{array}{l}\text { Incomplete } \\
\text { bolus transit } \\
\quad(\mathrm{n}=56)\end{array}$ & $\begin{array}{l}\text { Complete } \\
\text { bolus transit } \\
(\mathrm{n}=164)\end{array}$ & $P$-value \\
\hline \multirow[t]{4}{*}{$20 \mathrm{mmHg}$} & Normal & 7 & 56 & \\
\hline & $\begin{array}{l}\text { Focal peristaltic } \\
\text { hypotension }\end{array}$ & 6 & 65 & 0.604 \\
\hline & $\begin{array}{l}\text { Diffuse peristaltic } \\
\text { hypotension }\end{array}$ & 6 & 43 & 0.815 \\
\hline & Absent peristalsis & 37 & 0 & $<0.001$ \\
\hline \multirow[t]{4}{*}{$30 \mathrm{mmHg}$} & Normal & 5 & 30 & \\
\hline & $\begin{array}{l}\text { Focal peristaltic } \\
\text { hypotension }\end{array}$ & 7 & 70 & 0.410 \\
\hline & $\begin{array}{l}\text { Diffuse peristaltic } \\
\text { hypotension }\end{array}$ & 7 & 64 & 0.499 \\
\hline & Absent peristalsis & 37 & 0 & $<0.001$ \\
\hline
\end{tabular}

${ }^{a} P$-values were calculated using $\chi^{2}$ test comparing each peristaltic pattern to normal peristalsis. 

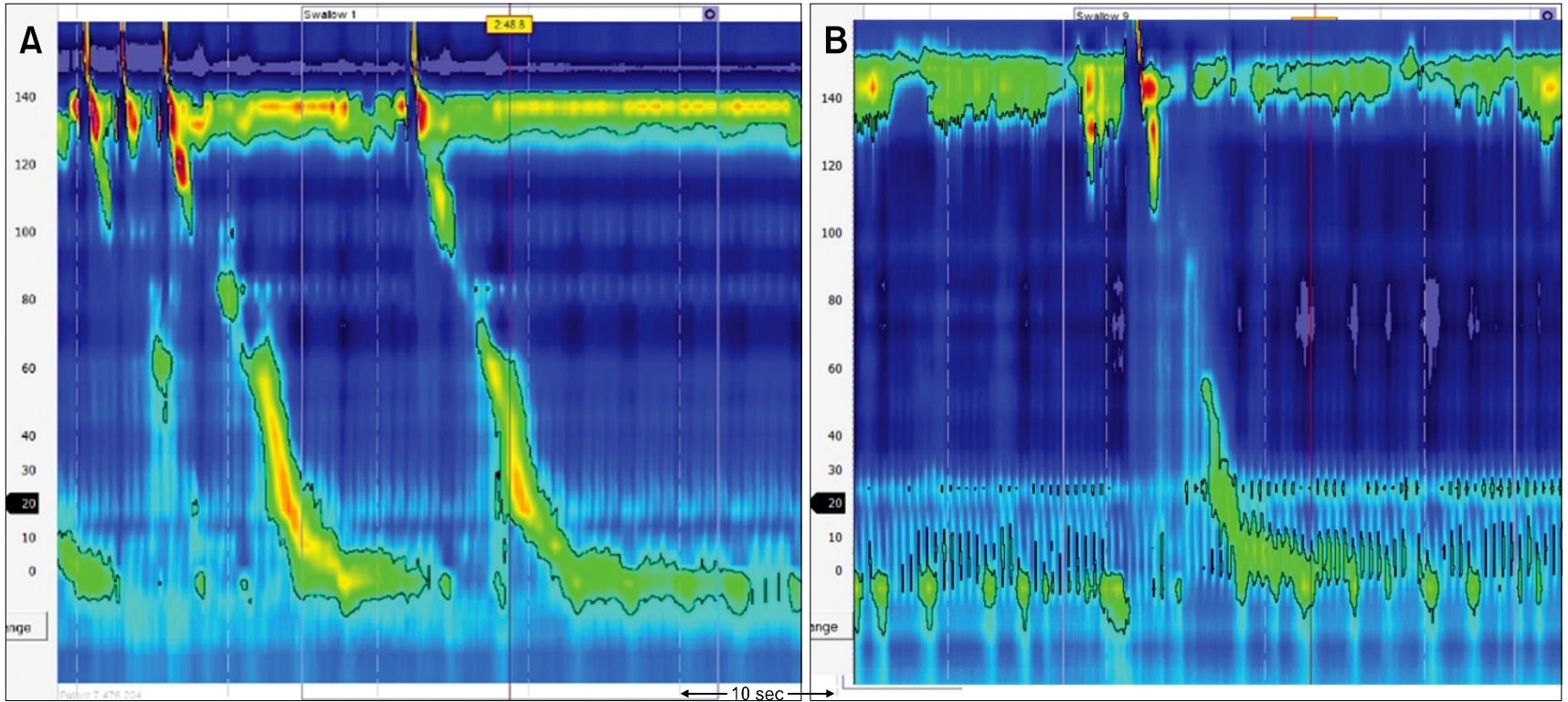

Figure. High-resolution manometry pressure topography plot of dysphagia patients on isobaric contours of $20 \mathrm{mmHg}$. (A) A normal peristaltic contraction with $2 \mathrm{~cm}$ in defect size shows that intrabolus pressure (IBP) is $13.1 \mathrm{mmHg}$ and integrated relaxation pressure (IRP) is $5.8 \mathrm{mmHg}$. (B) A diffuse peristaltic hypotension with $11.1 \mathrm{~cm}$ in defect size shows that IBP is $9.5 \mathrm{mmHg}$ and IRP is $1.5 \mathrm{mmHg}$. It seems that complete bolus transit occurs in both normal peristaltic contraction and diffuse peristaltic contraction.

IBP and EGJ relaxation pressure determines the effectiveness of esophageal emptying. ${ }^{1}$ Despite the importance of this delicate balance, there has been little focus on measuring the relationship between IBP and EGJ relaxation pressure. The lack of information likely does not represent a lack of interest but rather a lack of precision in conventional manometric equipment to accurately measure dynamic IBP variations. HRM has a greatly increased number of recording sites to allow a spatial continuum of intraluminal pressure after interpolating between adjacent sensors. ${ }^{17,18}$ HRM pressure sensors can simultaneously monitor IBP and EGJ relaxation pressure. Therefore, HRM may be considered to provide a reliable measurement of IBP and its relationship with EGJ relaxation pressure. Tutuian and Castell ${ }^{4}$ suggested that normal bolus transit can occur in the context of a poorly relaxing EGJ if peristalsis can generate a sufficient IBP to overcome EGJ obstruction pressure.We hypothesized that when IBP overcomes IRP, bolus transit may occur, and we analyzed relationships between peristalsis patterns and bolus transit. However, comparison between normal peristalsis and hypoperistalsis revealed that there were no statistically significant differences in bolus transit between normal peristalsis and hypoperistalsis. Physical factors that have impacts on intraluminal pressure may be further considered.

In conclusion, assuming that bolus transit was occurring when IBP was sufficient to overcome IRP, peristalsis pattern may not predict bolus transit in patients with dysphagia. However, further prospective studies are needed to evaluate the relationship between peristalsis pattern and bolus transit using HRM with impedance in patients with dysphagia.

\section{References}

1. Ren J, Massey BT, Dodds WJ, et al. Determinants of intrabolus pressure during esophageal peristaltic bolus transport. Am J Physiol 1993; 264(3 Pt 1):G407-G413.

2. Pal A, Williams RB, Cook IJ, Brasseur JG. Intrabolus pressure gradient identifies pathological constriction in the upper esophageal sphincter during flow. Am J Physiol Gastrointest Liver Physiol 2003;285:G1037-G1048.

3. Omari T, Bakewell M, Fraser R, Malbert C, Davidson G, Dent J. Intraluminal micromanometry: an evaluation of the dynamic performance of micro-extrusions and sleeve sensors. Neurogastroenterol Motil 1996;8:241-245.

4. Tutuian R, Castell DO. Combined multichannel intraluminal impedance and manometry clarifies esophageal function abnormalities: study in 350 patients. Am J Gastroenterol 2004;99:1011-1019.

5. Ghosh SK, Pandolfino JE, Kwiatek MA, Kahrilas PJ. Oesophageal peristaltic transition zone defects: real but few and far between. Neurogastroenterol Motil 2008;20:1283-1290.

6. Kahrilas PJ, Ghosh SK, Pandolfino JE. Esophageal motility disorders in terms of pressure topography: the Chicago Classification. J Clin Gastroenterol 2008;42:627-635. 
7. Ghosh SK, Kahrilas PJ, Lodhia N, Pandolfino JE. Utilizing intraluminal pressure differences to predict esophageal bolus flow dynamics. Am J Physiol Gastrointest Liver Physiol 2007;293:G1023-G1028 .

8. Pandolfi no JE, Ghosh SK, Lodhia N, Kahrilas PJ. Utilizing intraluminal pressure gradients to predict esophageal clearance: a validation study. Am J Gastroenterol 2008;103:1898-1905.

9. Massey BT, Dodds WJ, Hogan WJ, Brasseur JG, Helm JF. Abnormal esophageal motility. An analysis of concurrent radiographic and manometric findings. Gastroenterology 1991;101:344-354.

10. Crist J, Gidda JS, Goyal RK. Intramural mechanism of esophageal peristalsis: roles of cholinergic and noncholinergic nerves. Proc Natl Acad Sci USA 1984;81:3595-3599.

11. Ghosh SK, Janiak P, Schwizer W, Hebbard GS, Brasseur JG. Physiology of the esophageal pressure transition zone: separate contraction waves above and below. Am J Physiol Gastrointest Liver Physiol 2006;290:G568-G576.

12. Meyer GW, Austin RM, Brady CE 3rd, Castell DO. Muscle anatomy of the human esophagus. J Clin Gastroenterol 1986;8:131-134.

13. Roman C, Gonella J. Extrinsic control of digestive tract motility. 2nd ed. New York: Raven Press 1987.

14. Ghosh SK, Pandolfino JE, Zhang Q, Jarosz A, Shah N, Kahrilas PJ. Quantifying esophageal peristalsis with highresolutionmanometry: a study of 75 asymptomatic volunteers. Am J Physiol Gastrointest Liver Physiol 2006;290:G988-G997.

15. Fox M, Hebbard G, Janiak P, et al. High-resolution manometry predicts the success of oesophageal bolus transport and identifies clinically important abnormalities not detected by conventional manometry. Neurogastroenterol Motil 2004;16:533-542.

16. Ghosh SK, Janiak P, Fox M, Schwizer W, Hebbard GS, Brasseur JG. Physiology of the esophageal transition zone in the presence of chronic bolus retention: studies using concurrent high-resolution manometry and digital fluoroscopy. Neurogastroenterol Motil 2008;20:750-759.

17. Clouse RE, Parks T, Haroian L, Zakko SF. Development and clinical validation of a solid-state high-resolution pressure measurement system for simplified and consistent esophageal manometry. Am J Gastroenterol 2003;98:S32-S33.

18. Clouse RE, Staiano A. Topography of the esophageal peristaltic pressure wave. Am J Physiol 1991;261(4 Pt 1):G677-G684. 